RAD Conference Proceedings, vol. 3, pp. 191-196, 2018

ISSN 2466-4626 (online) | DOI: 10.21175/RadProc.2018.41

www.rad-proceedings.org

\title{
EVALUATION OF ELECTROMAGNETIC FIELD EXPOSURE OF GENERAL PUBLIC AROUND TELECOMMUNICATION SOURCES
}

\author{
M. Ivanova ${ }^{1}$, Ts. Shalamanova ${ }^{*}$, V. Zaryabova $^{1}$, P. Ivanova $^{1}$, Iv. Topalova ${ }^{1}$, M. Israel ${ }^{1,2}$ \\ ${ }^{1}$ National Centre of Public Health and Analyses, Sofia, Bulgaria \\ ${ }^{2}$ Medical University-Pleven, Pleven, Bulgaria
}

\begin{abstract}
The exposure to radiofrequency electromagnetic fields (RF EMF) in the living environment is due to variety of sources, predominantly for telecommunications - radio and TV stations and base stations for mobile communication emitting in the frequency range from $100 \mathrm{kHz}$ to several $\mathrm{GHz}$. In recent years research has shown that such systems have significantly increased RF EMF levels in urban areas compared to those measured in the 1980 , when the major sources in the environment were analogue radio and television stations. The aim of the report is to present the assessment of electromagnetic field exposure to the general public from telecommunication sources on the territory of the country. Separate data from measurement and exposure assessment of RF EMF levels around base stations for mobile communication and Radio and TV stations are considered. The data contain results of spot measurements of RF EMF levels emitted by separate base stations for mobile communication and radio and TV stations and spot measurements in areas with a high density of RF EMF sources - 105 regions in the country. It covers 1376 base stations and 280 radio and TV stations. The received results show that RF EMF levels are below the permissible levels according to the national legislation. Higher values, within the exposure limits, are found in areas with large number of sources or when the emitters are mounted on small height, but in such cases the values are less than $30 \%$ of those in national legislation. Compared to the European legislation the registered RF EMF levels are below $1 \%$ of exposure limits. The measured values of the electric field strengths and power densities around the radio and television stations are within the exposure limits according to the national legislation. Values above exposure limits have been found in 1-2\% of cases, but they were measured outside the urban areas where only incidental stay of the general public is possible. In comparison to the European legislation (Council Recommendation 1999/519/EC) measured values of the electric field strength and power density around radio and TV stations are well below the limit values.
\end{abstract}

Key words: Base stations, electromagnetic fields, exposure assessment, exposure limit values, radio and TV stations

\section{INTRODUCTION}

Exposure to radiofrequency electromagnetic fields (RF EMF) in the environment is a result of a variety of sources, predominantly for telecommunication radio and television stations and base stations for mobile communications emitting in the frequency range from $100 \mathrm{kHz}$ to several GHz. Recent research has shown that such systems have significantly increased RF EMF levels in urban areas compared to those measured in the 1980 s, when the major sources in the environment were the analogue radio and television stations $[6,7,10,13]$.

Data collected from campaigns for point and monitoring measurements show that the introduction of new technologies after $2 \mathrm{G}$ systems has not led to a significant increase in the RF EMF levels in the environment. [6,13]

A report of the Scientific Committee on Emerging and Newly Identified Health Risks to the European
Commission (SCENIHR) of 2015 [12] presents a summary of studies on electromagnetic exposure around radio and television transmitters showing that, despite the lower emitted power after digitization, a statistically significant increase in the average EMF exposure in the frequency range used for television broadcasts is reported. According to the authors, the reason for the increase in exposure is the introduction of digital video broadcasting (DVB-T). On the other hand, the transition from analogue to digital audio distribution (DAB) results in a 10 fold reduction in the average exposure in the range used for broadcasting [11].

According to the current national legislation for each stationary source of RF EMF emitting in the environment onsite measurements are needed to be made. To comply with the requirements of the legislation, non-selective spot measurements of the EMF are performed. This method of obtaining data concerning general public exposure is mostly used by different countries and organizations, especially when it comes to RF EMF levels control. Broadband (non-

\footnotetext{
*ts.shalamanova@gmail.com
} 
selective) measurements are recommended because such measurements give information about the total field from all sources at the measuring point.

\section{AIM}

The aim of the paper is to present and analyze the results of spot measurements and evaluation of the electromagnetic exposure from telecommunication sources spread on the territory of the country. Due to their specificity as sources measurement around base stations for mobile communication and Radio and TV stations are separately considered and analyzed.

\section{MATERIALS AND METHODS}

\subsection{Methods}

Methods for measuring EMF levels in the vicinity of base stations for mobile communication and radio and TV stations.

Non-selective methods for spot measurements of EMF levels in populated areas and outside settlements.

Methods for analyzing and processing data from spot measurements of EMF levels.

Methods for collecting and summarizing information from spot measurements.

The measurements are performed according to the requirements of EN ISO 50492 [2], EN ISO 50413 [3] and EN ISO 50400 [4], defining measurement methods, equipment, etc. for adequate EMF exposure assessment in the vicinity of communication sources.

The measurement points are selected according to "Method for determination of EMF measurement and evaluation points in populated areas identified as "with high density of EMF sources" [8].

The method requires preliminary and detailed information about the location of the emitters, as well as an electronic geographic map of the selected urban area. EMF measurement and evaluation points are selected to determine exposure to EMF from multiple sources emitting in different frequency ranges and with different power and field configurations.

The territory of a settlement is divided into quadrants with an area of approximately $1.5 \mathrm{~km}^{2}$ using Googlemaps product. EMF emitters are positioned in each area under investigation.

Measurement points for which higher EMF values or complex EMF exposure are expected are selected, following the criteria: urban area with high density of RF EMF sources - base stations for mobile communication, VHF, TV stations and more (the available source information is used); buildings with more than one source; region with a density of users of wireless telecommunications services.

The measurement points are selected to meet the "worst case" criterion in terms of exposure of the population - closest building, direction of the emitting sector from the antenna system, how the 192 electromagnetic energy falls to the place of measurement.

\subsection{Measurement equipment}

The measurements were performed using the following measurement equipment:

- NARDA NBM 550, NARDA Safety Test Solutions, Germany, with isotropic probe $\mathrm{EF} 1891$, frequency range from $3 \mathrm{MHz}$ up to $18 \mathrm{GHz}$

- NARDA EMR 21C, NARDA Safety Test Solutions, Germany, with isotropic probe type 18 , frequency range from $100 \mathrm{kHz}$ up to $3 \mathrm{GHz}$.

- NFM1, Pracitronik, Germany, with anisotropic probe, frequency range $60 \mathrm{kHz}$ up to $350 \mathrm{MHz}$.

\subsection{Studied objects}

\subsubsection{Base stations for mobile communication}

The survey covers more than $70 \%$ of the registered base stations for mobile communication on the territory of the Republic of Bulgaria, which at the start of the survey amounted to 6282. This includes processing of existing measurement data for 3553 sites as well as measuring and processing the results for 1376 base stations for mobile communication during the survey.

Measurements made during the study include the following:

- $\quad$ Spot measurements of EMF levels emitted by separate base stations for mobile communication;

- Spot measurements in the investigation of areas -105 regions in the country, identified as "with high density of EMF sources".

\subsubsection{Radio and TV stations}

The survey covers 280 radio and TV stations located all over the country. During the study the dossiers of the sites, including their technical characteristics, evaluated hygienic safety zones and measurement results were investigated.

\section{RESULTS AND DISCUSSION}

\subsection{Base stations for mobile communication}

\subsubsection{Data processing from RF EMF level} measurements around base stations for mobile communication

Data from spot measurements of EMF levels around base stations for mobile communication for 3553 objects were processed. The power density values obtained from the processing of the available data are in the range $0.1-0.6 \mu \mathrm{W} / \mathrm{cm}^{2}$, with the median of $0.2 \mu \mathrm{W} / \mathrm{cm}^{2}$. The reported results are below 
the limit value according to the national legislation, Ordinance No 9 of March 1991 [9], $10 \mu \mathrm{W} / \mathrm{cm}^{2}$ for the frequency range used for mobile communication.

\subsubsection{Spot measurements of RF EMF around base} stations for mobile communication

Method for the determination of the points of measurement and evaluation of RF EMF in populated areas, defined as "with high density of EMF sources" developed for the aims of the study was applied for carrying out a survey of 105 regions in the country identified "with high density of EMF sources". Records of 1376 base stations for mobile communication were collected, comprising the technical features of the objects, hygienic safety zones, and detailed spot measurements. The research includes 48 districts in Sofia. The boundaries of the studied areas are avenues, streets or span with an area about $1.5 \mathrm{~km} 2$. Region surveys also cover 2 digital televisions. In the surveyed areas measurements were performed in 1175 points. Depending on the size of the city, an area contains between 3 and 24 RF EMF sources.

The areas surveyed are both in a central city area, as well as in residential or urban areas.

Each source of the RF EMF and the results of the performed measurements were mapped to an electronic map in the register of the sources of electromagnetic https://emp.ncpha.government.bg/.

For each of the surveyed areas selected according to the described methodology, electronic maps of the territory covered were prepared. Cards are mapped to the sources of EMF (base stations, TV towers, etc.) with their exact location. To carry out the study, the locations where RF EMF levels to be measured were generated in advance. Measurements of EMF were made in the settlements, the points being described by location, incl. geographic coordinates, street address, block / building number.

Figure 1 presents electronic maps of selected areas with a high density of RF EMF sources showing the location of the EMF sources and the measurement points.

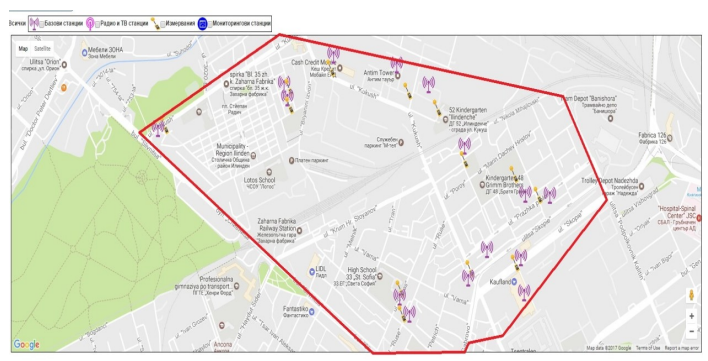

Figure 1. Electronic map of a surveyed area with a marked location of the EMF sources and points of measurement

The maximal measured values of the EMF power density for all regions (regions are numbered from 1 to 105) are plotted in Figure 2.
The maximum measured values in the surveyed areas are below the permissible value according to the national legislation, Ordinance No. 9/14.03.1991 - 10 $\mu \mathrm{W} / \mathrm{cm}^{2}$ [9]. Prevailing values are below $1.0 \mu \mathrm{W} / \mathrm{cm}^{2}$, i.e., less than $10 \%$ of the permissible one, according to the Bulgarian legislation.

Values above $1.0 \mu \mathrm{W} / \mathrm{cm}^{2}$ were measured in three of the surveyed areas. The reason for them is the lower level of mounting of the emitters. In one of the areas, the higher value is due to the presence of a large number of sources in the area (20 sources) and also to a low-mounted source (on a street lighting pole).

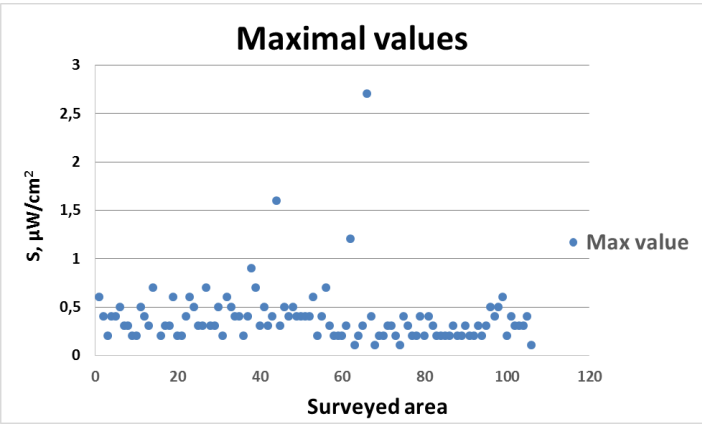

Figure 2. Maximal measured values of EMF power density in the surveyed areas

The analysis of the measured values and technical and situational characteristics of the sources shows that higher registered EMF power density values are due to the overlapping of the radiation patterns, the azimuth matching, the use of large electric tilts of the antenna radiation diagrams due to the specificity of the architecture of the mobile communication networks, the use of a common antenna feeder system by more than one mobile operator. There are cases where they are due to sources mounted at low altitude (low buildings, masts, street lighting poles).

With regard to Council Recommendation [1], all measured RF EMF power density values are below $1 \%$ of the reference levels for bandwidth used for mobile communications, respectively $450 \mathrm{~mW} / \mathrm{cm}^{2}$ for $900 \mathrm{MHz}$; $900 \mu \mathrm{W} / \mathrm{cm}^{2}$ for $1800 \mathrm{MHz}$ and $1000 \mu \mathrm{W} / \mathrm{cm}^{2}$ above $2000 \mathrm{MHz}$.

\subsection{Radio and TV stations}

Radio and television stations are complex objects that contain multiple sources emitting in different frequency ranges for which, due to the specificity of electromagnetic radiation, different parameters are used for maximal permissible values: electric field strength for the range $30-300 \mathrm{MHz}(3 \mathrm{~V} / \mathrm{m})$ and power density for the $300 \mathrm{MHz}$ to $30 \mathrm{GHz}$ range (10 $\left.\mu \mathrm{W} / \mathrm{cm}^{2}\right)$. For this reason, for radio and TV stations containing sources in the two frequency range (266) at each surveyed point measurements were made with several devices mentioned above.

This allows the contributions of the sources emitting from 30 to $300 \mathrm{MHz}$ to be separated. 
Figure 3 shows the maximal power density values measured in the vicinity of radio and television stations by intervals, and Figure 4 presents the relative distribution of the measured maximum values by intervals.

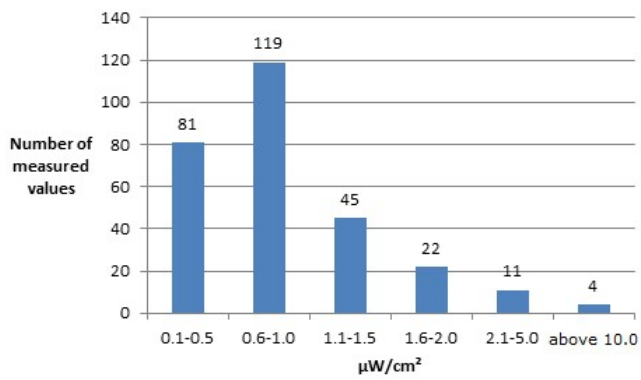

Figure 3. Power density values measured in the vicinity of radio and TV stations

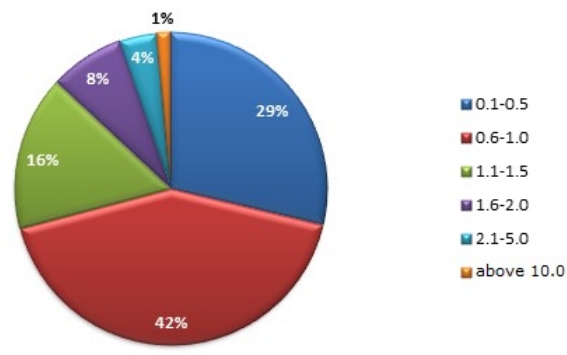

Figure 4. Relative distributions of power density values measured in the vicinity of radio and TV stations at the intervals considered

Figure 5 presents the distribution of the maximal values of the electric field strength, measured in the vicinity of 266 radio and TV stations containing sources emitting in the frequency range $30-300$ MHz. Figure 6 presents the relative distribution of the measured values by intervals.

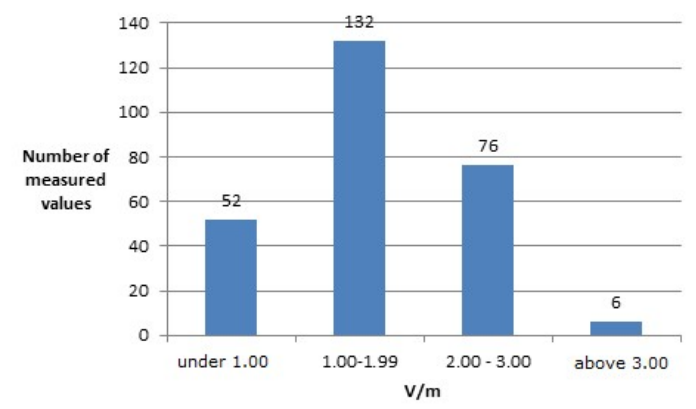

Figure 5. Distribution of the electric field strength values, measured in the vicinity of radio and TV stations

As can be seen from the presented results, the measured values of the EMF power density are mainly in the ranges of $0.1-0.5 \mu \mathrm{W} / \mathrm{cm}^{2}(29 \%)$ and $0.5-1.0$ $\mu \mathrm{W} / \mathrm{cm}^{2}$ (42\%), representing up to $10 \%$ of the maximum permissible value according to the national legislation [Ordinance No 9/1991].

In $1 \%$ of cases - for 4 sites, power density values exceeding the maximum permissible value were registered.

In terms of electric field strength values, they are predominantly in the range of $1.0-1.99 \mathrm{~V} / \mathrm{m}(50 \%)$ and $2.0-3.0 \mathrm{~V} / \mathrm{m}(29 \%)$, with $98 \%$ the cases do not exceeding the maximum permissible value $3 \mathrm{~V} / \mathrm{m}$ for the radiofrequency range according to Ordinance No. 9/1991 [9].

In $2 \%$ of the cases - for 6 sites, measured electric field strengths are above the maximal permissible values. Exceeding the maximum permissible values for the electric field strength and power density have been established for complex objects, such as radio relay stations and a radio TV center, with a number of high-power emitters outside the populated areas. Mostly workers, not the inhabitants, remain in the vicinity of the mentioned sites. The closest settlements are located outside the hygienic safety zones of the described sites.

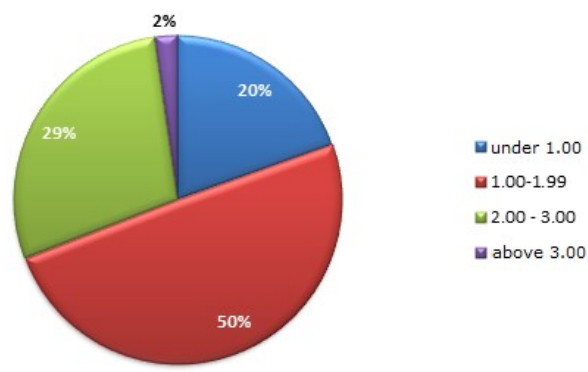

Figure 6. Distribution of the measured electric field strength values at the considered intervals

The comparison of the results obtained with the Council Recommendation 1999/519/EC [1] for the two frequency ranges shows that they are significantly lower than the reference levels: $25 \mathrm{~V} / \mathrm{m}$ for the frequency range $10-400 \mathrm{MHz}$; from $200-1000$ $\mu \mathrm{W} / \mathrm{cm}^{2}$ for the frequency range $400 \mathrm{MHz}-2 \mathrm{GHz}$.

\section{CONCLUSION}

The analysis of the results and the evaluation of the electromagnetic exposure show the following:

The measured EMF levels emitted by base stations for mobile communication are within the maximal permissible values according to the national legislation. Higher values (within the maximal permissible values) are registered in areas with a large number of sources in one region or in the presence of lower mounted emitters (for example, street lighting poles), but in these cases the values are below 30\% of those set in the national legislations. Compared to European legislation, the measured EMF levels are below $1 \%$ for the frequencies around $900 \mathrm{MHz}$ and 
well below $1 \%$ of the limit values for the other frequency ranges used for mobile communication.

The measured values of the electric field strengths and the power density around the radio and television stations are within the 1 maximal permissible values according to the national legislation. Values above permissible limits have been found in $1-2 \%$ of cases, but they refer to the areas outside settlements where only incidental population stay is possible.

Compared to the European legislation (EU Recommendation 1999/519/EC), the measured values of the electric field strengths and the power densities around radio and television stations are well below the reference levels.

The Applied Method for survey of EMF levels in areas identified as "with high density of EMF sources" will contribute to the improvement of the control by setting the relevant points of measurement of the electronic a geographic map and an electronic register of EMF sources meanwhile raising awareness of the population through direct input and visibility of measurement data, thereby improving information on exposure from sources of the EMF in the country, as well as the ways of its dissemination.

Present study: The present study was conducted under the project "Improving control and information systems in risk prevention and healthcare", BGo7 Program: "Public Health Initiatives" with the financial contribution of the Norwegian Financial Mechanism 2009-2014 and EEA Financial Mechanism 2009-2014.

Acknowledgements: We would like to thank to Dipl. Eng. Hristina Petkova who helped us to collect information, to present the results.

\section{REFERENCES}

1. The Council of the European Union. (Jul. 12, 1999). 1999/519/EC Council Recommendation of 12 July 1999 on the limitation of exposure of the general public to electromagnetic fields ( $\mathrm{O} \mathrm{Hz}$ to $300 \mathrm{GHz}$ ).

Retrieved form: https://publications.europa.eu/en /publication-detail/-/publication/9509bo4f-1dfo4221-bfa2-c7af77975556/language-en

Retrieved on: May 15, 2018

2. Basic standard for the in-situ measurement of electromagnetic field strength related to human exposure in the vicinity of base stations, EN ISO 50492:2008, Jan. 1, 2008.

Retrieved from: https://infostore.saiglobal.com/e

n-gb/Standards/BS-EN-50492-2008-

235283 SAIG_BSI_BSI 550344/;

Retrieved on: May 15, 2018

3. Basic standard on measurement and calculation procedures for human exposure to electric, magnetic and electromagnetic fields $(\mathrm{o} \mathrm{Hz}-300$ $\mathrm{GHz}$, EN ISO 50413:2008, Jan. 1, 2008.

Retrieved from: https://infostore.saiglobal.com/e n-gb/standards/i-s-en-50413-2008-

873723 SAIG NSAI NSAI 2077363/;

Retrieved on: May 15, 2018
4. Basic standard to demonstrate the compliance of fixed equipment for radio transmission (11O $\mathrm{MHz}$ - $40 \mathrm{GHz}$ ) intended for use in wireless telecommunication networks with the basic restrictions or the reference levels related to general public exposure to radio frequency electromagnetic fields, when put into service, EN ISO 50400:2006, Jun. 26, 2006.

Retrieved from: https://infostore.saiglobal.com/p review/is/en/2006/i.s.en50400-2006\%2Ba12012.pdf?sku $=680553$;

Retrieved on: May 15, 2018

5. The European Parliament. (Apr. 2, 2009). 2008/2211(INI) Resolution of 2 April 2009 on health concerns associated with electromagnetic fields.

Retrieved from: http://www.europarl.europa.eu/si des/getDoc.do?pubRef=-//EP//TEXT+TA+P6$\mathrm{TA}-2009-0216+0+\mathrm{DOC}+\mathrm{XML}+\mathrm{Vo} / / \mathrm{EN}$

Retrieved on: May 15, 2018

6. M. Ivanova, Ts. Shalamanova, "Measurements of $\mathrm{RF}$ radiation around base stations for mobile communication in Bulgaria," J. Environ. Prot. Ecol, vol. 6, no. 2, pp. 328 - 336, Jan. 2005.

Retrieved from: http://www.jepe-journal.info/vol6-no-2;

Retrieved on: May 15, 2018

7. W. Joseph, L. Verloock, F. Goeminne, G. Vermeeren, L. Martens, "Assessment of general public exposure to LTE and RF sources present in an urban environment," Bioelectromagnetics, vol. 31 , no. 7, pp. $576-579$, Oct. 2010.

DOI: $10.1002 /$ bem.20594 PMID: 20607741

8. M. Israel, Iv. Topalova, Ts. Shalamanova, M. Ivanova, V. Zaryabova, "Methods for selection of measurement points in urban areas with high density of EMF sources and such with "sensitive places and buildings"," J. Biomed. Clin. Res., vol. 8, no. 1, Suppl. 1, 2015.

Retrieved from: https://ephconference.eu/reposit ory/countries/Abstract Book Vol 8-1Suppl.pdf; Retrieved on: May 12, 2018

9. Министерство на здравеопазването (14.03.1991). Наредба № 9 от 14.03 .1991 г. за пределно допустими нива на електромагнитни полета в населени територии и определяне на хигиеннозащитни зони около излъчващи обекти. (Ministry of Health. (Mar. 14, 1991). Ordinance No. 9 from 14.03.1991 on the limit values of electromagnetic fields in populated areas and the determination of hygienic-protective zones around radiating objects.)

Retrieved from:

http://econ.bg/Нормативни-актове/Наредба-9от-14-03-1991-г-за-пределно-допустими-нивана-електромагнитни-полета-в-населениl.l i.128561 at.5.html;

Retrieved on: May 15, 2018

10. J. T. Rowley, K. H. Joyner, "Comparative international analysis of radiofrequency exposure surveys of mobile communication radio base stations," J. Expo. Sci. Environ. Epidemiol., vol. 22, no. 3, pp. 304 - 315, May-Jun. 2012.

DOI: $10.1038 /$ jes.2012.13

PMID: 22377680

PMCID: 3347802

11. M. Schubert, C. Bornkessel, M. Wuschek, P. Schimdt, "Exposure of the general public to digital broadcast transmitters compared to 
M. Ivanova et al., Evaluation of electromagnetic field exposure, RAD Conf. Proc., vol. 3, 2018, 191-196

analogue ones," Radiat. Prot. Dosim., vol. 124,

no. 1, pp. 53 - 57, Jul. 2007.

DOI: $10.1093 / \mathrm{rpd} / \mathrm{ncm} 337$

PMid: 17617635

12. Opinion on potential health effects of exposure to electromagnetic fields (EMF), SCENIHR Opinion, WHO, Switzerland, 2016.

DOI: $10.2772 / 75635$
13. Ts. Shalamanova et al., "Results of Measurements of Electromagnetic Fields around Base Stations fo Mobile Communication in Bulgaria," in Proc., $9^{\text {th }}$ Nat. Conf. Biomedical Physics and Engineering, Bulgaria, 2004, pp. 129 - 134 . 